\title{
Emotional Intelligence and the Transformation- Centered Leadership of the Organizations' Managers: Case Study of the Governmental Banks' Managers of the Fifth Zone of Tehran Municipality
}

\author{
${ }^{1}$ Hirad Nazari*, ${ }^{2}$ Seyyed Jalil Madani \\ ${ }^{1}$ Shafagh university Hall, Iran \\ 2Mazandaran University, Iran \\ *Hirad.nazari@yahoo.com
}

\begin{abstract}
This research has dealt with the study of the relationship between the concept of the emotional intelligence and transformation- centered leadership in the governmental banks of the fifth zone of Tehran municipality. By conducting the preliminary studies and initial surveys regarding the basic attributes of the transformation- centered leadership, a few components were presented for the transformation- centered leadership. Based on these components, one main hypothesis and five sub hypotheses were compiled and tested. The results of testing the first to fifth sub hypotheses suggest that there exists a significant relationship between the emotional intelligence with and the components of charisma, inspiration, ideal behaviors, mental encouragement and individual considerations in the assurance level of $95 \%$.
\end{abstract}

\section{Keywords: Emotional intelligence, Transformation- centered leadership, Bank}

\section{Introduction}

Emotional intelligence (EI) is the ability to identify, assess, and control the emotions of oneself, of others, and of groups. Various models and definitions have been proposed of which the ability and trait EI models are the most widely accepted in the scientific literature. Ability EI is usually measured using maximum performance tests and has stronger relationships with traditional intelligence, whereas trait EI is usually measured using self-report questionnaires and has stronger relationships with personality. Criticisms have centered on whether the construct is a real intelligence and whether it has incremental validity over IQ and the Big Five personality dimensions. The earliest roots of emotional intelligence can be traced to Charles Darwin's work on the importance of emotional expression for survival and, second, adaptation. In the 1900s, even though traditional definitions of intelligence emphasized cognitive aspects such as memory and problem-solving, several influential researchers in the intelligence field of study had begun to recognize the importance of the non-cognitive aspects. For instance, as early as 1920, E.L. Thorndike used the term social intelligence to describe the skill of understanding and managing other people. Similarly, in 1940 David Wechsler described the influence of non-intellective factors on intelligent behavior, and further argued that our models of intelligence would not be complete until we could adequately describe these factors. In 1983, Howard Gardner's Frames of Mind: The Theory of Multiple Intelligences, Barling, et al. (2000) introduced the idea of multiple intelligences which included both interpersonal intelligence(the capacity to understand the intentions, motivations and desires of other people) and intrapersonal intelligence (the capacity to understand oneself, to appreciate one's feelings, fears and motivations). In Gardner's view, traditional types of intelligence, such as IQ, fail to fully explain cognitive ability. Thus, even though the names given to the concept varied, there was a common belief that traditional definitions of intelligence were lacking in ability to fully explain performance outcomes.

The first use of the term "emotional intelligence" is usually attributed to Wayne Payne's doctoral thesis, A Study of Emotion: Developing Emotional Intelligence from 1985. However, prior to this, the term "emotional intelligence" had appeared in (Leuner, 1966). The distinction between trait emotional intelligence and ability emotional intelligence was introduced in 2000. As one of the pillars of the financial system, banking industry has experienced the various managers since formation up to now whom they have searched for the profitability, presentation of the quality services and customer- centering. The extensive changes and transformations in this industry, perspective of intensifying the competition in it, movement toward the economical liberation and approach to the international markets have created the conditions, which the leadership in these organizations has been gained more significance. Results of the past researches show that the emotional intelligence is one of the important concepts, which seems very 
useful and necessary in the domain of the relationships of employees and managers. Success of the today organizations is dependent on the intellectual capability of their leader extensively. One of the new theories of the leadership is the theory of transformation- centered leadership. This leadership achieves when a leader motivates the followers for the common vision, encourages them to reach the perspective, puts emphasis on the followers to grow and creates the commitment, as a model, in the individuals.

The writers try to deal with the study and assessment of the relationship of the emotional intelligence with transformation- centered leadership of the banks' directors; therefore, with regard to the subject of the research, employers of the banks can exploit and conclude from the findings of this research. Substantial disagreement exists regarding the definition of EI, with respect to both terminology and operationalizations. Currently, there are three main models of EI:

- Ability EI model

- Mixed models of EI (usually subsumed under trait EI)

- Trait EI model

Different models of EI have led to the development of various instruments for the assessment of the construct. While some of these measures may overlap, most researchers agree that they tap different constructs.

Ability model: Salovey and Mayer's conception of EI strives to define EI within the confines of the standard criteria for a new intelligence. Following their continuing research, their initial definition of EI was revised to "The ability to perceive emotion, integrate emotion to facilitate thought, understand emotions and to regulate emotions to promote personal growth." The ability-based model views emotions as useful sources of information that help one to make sense of and navigate the social environment. The model proposes that individuals vary in their ability to process information of an emotional nature and in their ability to relate emotional processing to a wider cognition. This ability is seen to manifest itself in certain adaptive behaviors. The model claims that EI includes four types of abilities:

- Perceiving emotions - the ability to detect and decipher emotions in faces, pictures, voices, and cultural artifacts-including the ability to identify one's own emotions. Perceiving emotions represents a basic aspect of emotional intelligence, as it makes all other processing of emotional information possible.

- Using emotions - the ability to harness emotions to facilitate various cognitive activities, such as thinking and problem solving. The emotionally intelligent person can capitalize fully upon his or her changing moods in order to best fit the task at hand.

- Understanding emotions - the ability to comprehend emotion language and to appreciate complicated relationships among emotions. For example, understanding emotions encompasses the ability to be sensitive to slight variations between emotions, and the ability to recognize and describe how emotions evolve over time.

- Managing emotions - the ability to regulate emotions in both ourselves and in others. Therefore, the emotionally intelligent person can harness emotions, even negative ones, and manage them to achieve intended goals.

The ability EI model has been criticized in the research for lacking face and predictive validity in the workplace.

Measurement of the ability model: The current measure of Mayer and Salovey's model of EI, the MayerSalovey-Caruso Emotional Intelligence Test (MSCEIT) is based on a series of emotion-based problemsolving items. Consistent with the model's claim of EI as a type of intelligence, the test is modeled on ability-based IQ tests. By testing a person's abilities on each of the four branches of emotional intelligence, it generates scores for each of the branches as well as a total score. Central to the four-branch model is the idea that EI requires attunement to social norms. Therefore, the MSCEIT is scored in a consensus fashion, with higher scores indicating higher overlap between an individual's answers and those provided by a worldwide sample of respondents. The MSCEIT can also be expert-scored, so that the amount of overlap is calculated between an individual's answers and those provided by a group of 21 emotion researchers. Although promoted as an ability test, the MSCEIT is unlike standard IQ tests in that its items do not have objectively correct responses. Among other challenges, the consensus scoring criterion means that it is impossible to create items (questions) that only a minority of respondents can solve, because, by definition, responses are deemed emotionally "intelligent" only if the majority of the sample has endorsed them. This and other similar problems have led some cognitive ability experts to question the definition of EI as a genuine intelligence. In a study by Føllesdal, the MSCEIT test results of 
111 business leaders were compared with how their employees described their leader. It was found that there were no correlations between a leader's test results and how he or she was rated by the employees, with regard to empathy, ability to motivate, and leader effectiveness. Føllesdal also criticized the Canadian company Multi-Health Systems, which administers the MSCEIT test. The test contains 141 questions but it was found after publishing the test that 19 of these did not give the expected answers. This has led Multi-Health Systems to remove answers to these 19 questions before scoring, but without stating this officially.

Mixed models: The model introduced by Daniel Goleman focuses on EI as a wide array of competencies and skills that drive leadership performance. Goleman's model outlines five main EI constructs (for more details see "What Makes A Leader" by Daniel Goleman, best of Harvard Business Review 1998):

- Self-awareness - the ability to know one's emotions, strengths, weaknesses, drives, values and goals and recognizes their impact on others while using gut feelings to guide decisions.

- Self-regulation - involves controlling or redirecting one's disruptive emotions and impulses and adapting to changing circumstances.

- Social skill - managing relationships to move people in the desired direction

- Empathy - considering other people's feelings especially when making decisions and

- Motivation - being driven to achieve for the sake of achievement.

Goleman includes a set of emotional competencies within each construct of EI. Emotional competencies are not innate talents, but rather learned capabilities that must be worked on and can be developed to achieve outstanding performance. Goleman posits that individuals are born with a general emotional intelligence that determines their potential for learning emotional competencies. Goleman's model of EI has been criticized in the research literature as mere "pop psychology" (Mayer, Roberts \& Barsade, 2008).

Measurement of the Emotional Competencies (Goleman) model: Two measurement tools are based on the Goleman model:

- The Emotional Competency Inventory (ECI), which was created in 1999, and the Emotional and Social Competency Inventory (ESCI), which was created in 2007.

- The Emotional Intelligence Appraisal, which was created in 2001 and which can be taken as a selfreport or 360-degree assessment.

Bar-On model of emotional-social intelligence (ESI): Bar-On defines emotional intelligence as being concerned with effectively understanding oneself and others, relating well to people, and adapting to and coping with the immediate surroundings to be more successful in dealing with environmental demands. Bar-On posits that EI develops over time and that it can be improved through training, programming, and therapy. Bar-On hypothesizes that those individuals with higher than average EQs are in general more successful in meeting environmental demands and pressures. He also notes that a deficiency in EI can mean a lack of success and the existence of emotional problems. Problems in coping with one's environment are thought, by Bar-On, to be especially common among those individuals lacking in the subscales of reality testing, problem solving, stress tolerance, and impulse control. In general, BarOn considers emotional intelligence and cognitive intelligence to contribute equally to a person's general intelligence, which then offers an indication of one is potential to succeed in life. However, doubts have been expressed about this model in the research literature (in particular about the validity of self-report as an index of emotional intelligence) and in scientific settings, it is being replaced by the trait emotional intelligence (trait EI) model discussed below.

Measurement of the ESI model: The Bar-On Emotional Quotient Inventory (EQ-i), is a self-report measure of EI developed as a measure of emotionally and socially competent behavior that provides an estimate of one's emotional and social intelligence. The EQ-i is not meant to measure personality traits or cognitive capacity, but rather the mental ability to be successful in dealing with environmental demands and pressures. One hundred and thirty three items (questions or factors) are used to obtain a Total EQ (Total Emotional Quotient) and to produce five composite scale scores, corresponding to the five main components of the Bar-On model. A limitation of this model is that it claims to measure some kind of ability through self-report items (for a discussion, see Matthews, Zeidner \& Roberts, 2001). The EQ-i has been found to be highly susceptible to faking (Grubb \& McDaniel, 2007).

Trait EI model: Soviet-born British psychologist Konstantin Vasily Petrides ("K. V. Petrides") proposed a conceptual distinction between the ability based model and a trait based model of EI and has been developing the latter over many years in numerous scientific publications. Trait EI is "a constellation of 
emotional self-perceptions located at the lower levels of personality." In lay terms, trait EI refers to an individual's self-perceptions of their emotional abilities. This definition of EI encompasses behavioral dispositions and self perceived abilities and is measured by self report, as opposed to the ability based model, which refers to actual abilities, which have proven highly resistant to scientific measurement. Trait EI should be investigated within a personality framework. An alternative label for the same construct is trait emotional self-efficacy. The trait EI model is general and subsumes the Goleman and Bar-On models discussed above. The conceptualization of EI as a personality trait leads to a construct that lies outside the taxonomy of human cognitive ability. This is an important distinction in as much as it bears directly on the operationalization of the construct and the theories and hypotheses that are formulated about it.

Measurement of the trait EI model: There are many self-report measures of EI, including the EQ-i, the Swinburne University Emotional Intelligence Test (SUEIT), and the Schutte EI model. None of these assess intelligence, abilities, or skills (as their authors often claim), but rather, they are limited measures of trait emotional intelligence. One of the more comprehensive and widely researched measures of this construct is the Trait Emotional Intelligence Questionnaire (TEIQue), which was specifically designed to measure the construct comprehensively and is available in many languages. The TEIQue provides an operationalization for the model of Petrides and colleagues that conceptualizes EI in terms of personality. The test encompasses 15 subscales organized under four factors: Well-Being, Self-Control, Emotionality, and Sociability. The psychometric properties of the TEIQue were investigated in a study on a Frenchspeaking population, where it was reported that TEIQue scores were globally normally distributed and reliable. The researchers also found TEIQue scores were unrelated to nonverbal reasoning (Raven's matrices), which they interpreted as support for the personality trait view of EI (as opposed to a form of intelligence). As expected, TEIQue scores were positively related to some of the Big Five personality traits (extraversion, agreeableness, openness, conscientiousness) as well as inversely related to others (alexithymia, neuroticism). A number of quantitative genetic studies have been carried out within the trait EI model, which have revealed significant genetic effects and heritabilities for all trait EI scores.[27] Two recent studies (one a meta-analysis) involving direct comparisons of multiple EI tests yielded very favorable results for the TEIQue.

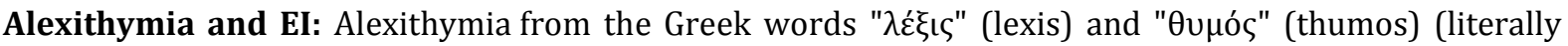
"lack of words for emotions") is a term coined by Peter Sifneos in 1973 to describe people who appeared to have deficiencies in understanding, processing, or describing their emotions. Viewed as a spectrum between high and low EI, the alexithymia construct is strongly inversely related to EI, representing its lower range. The individual's level of alexithymia can be measured with self-scored questionnaires such as the Toronto Alexithymia Scale (TAS-20) or the Bermond-Vorst Alexithymia Questionnaire (BVAQ) or by observer rated measures such as the Observer Alexithymia Scale (OAS).

\section{Criticisms of the theoretical foundation of EI}

EI cannot be recognized as a form of intelligence: Goleman's early work has been criticized for assuming from the beginning that EI is a type of intelligence. [Goleman] exemplifies more clearly than most the fundamental absurdity of the tendency to class almost any type of behavior as an 'intelligence'. If these five 'abilities' define 'emotional intelligence', we would expect some evidence that they are highly correlated; Goleman admits that they might be quite uncorrelated, and in any case if we cannot measure them, how do we know they are related? So the whole theory is built on quicksand: there is no sound scientific basis." Similarly, Locke (2005) claims that the concept of EI is in itself a misinterpretation of the intelligence construct, and he offers an alternative interpretation: it is not another form or type of intelligence, but intelligence - the ability to grasp abstractions-applied to a particular life domain: emotions. He suggests the concept should be re-labeled and referred to as a skill. The essence of this criticism is that scientific inquiry depends on valid and consistent construct utilization, and that before the introduction of the term EI, psychologists had established theoretical distinctions between factors such as abilities and achievements, skills and habits, attitudes and values, and personality traits and emotional states. Thus, some scholars believe that the term EImerges and conflates such accepted concepts and definitions.

EI has little predictive value: Landy (2005) claimed that the few incremental validity studies conducted on EI have shown that it adds little or nothing to the explanation or prediction of some common outcomes (most notably academic and work success). Landy suggested that the reason why some studies have 
found a small increase in predictive validity is a methodological fallacy, namely, that alternative explanations have not been completely considered: "EI is compared and contrasted with a measure of abstract intelligence but not with a personality measure, or with a personality measure but not with a measure of academic intelligence" (Landy, 2005). Similarly, other researchers have raised concerns about the extent to which self-report EI measures correlate with established personality dimensions. Generally, self-report EI measures and personality measures have been said to converge because they both purport to measure personality traits. Specifically, there appear to be two dimensions of the Big Five that stand out as most related to self-report EI - neuroticism and extroversion. In particular, neuroticism has been said to relate to negative emotionality and anxiety. Intuitively, individuals scoring high on neuroticism are likely to score low on self-report EI measures. The interpretations of the correlations between EI questionnaires and personality have been varied. The prominent view in the scientific literature is the Trait EI view, which re-interprets EI as a collection of personality traits.

\section{Criticisms of measurement issues}

Ability EI measures measure conformity, not ability: One criticism of the works of Mayer and Salovey comes from a study by Roberts et al. (2001), which suggests that the EI, as measured by the MSCEIT, may only be measuring conformity. This argument is rooted in the MSCEIT's use of consensus-based assessment, and in the fact that scores on the MSCEIT are negatively distributed (meaning that its scores differentiate between people with low EI better than people did with high EI).

Ability EI measures measure knowledge (not actual ability): Further criticism has been leveled by Brody (2004), who claimed that unlike tests of cognitive ability, the MSCEIT "tests knowledge of emotions but not necessarily the ability to perform tasks that are related to the knowledge that is assessed". The main argument is that even though someone knows how he should behave in an emotionally laden situation, it does not necessarily follow that the person could actually carry out the reported behavior.

Ability EI measures measure personality and general intelligence: New research is surfacing that suggests that ability EI measures might be measuring personality in addition to general intelligence. These studies examined the multivariate effects of personality and intelligence on EI and also corrected estimates for measurement error (which is often not done in some validation studies). For example, a study by Schulte, Ree \& Carretta (2004), showed that general intelligence (measured with the Wonderlic Personnel Test), agreeableness (measured by the NEO-PI), as well as gender had a multiple R of .81 with the MSCEIT. This result has been replicated by Fiori \& Antonakis (2011); they found a multiple R of .76 using Cattell's "Culture Fair" intelligence test and the Big Five Inventory (BFI); significant covariates were intelligence (standardized beta $=.39$ ), agreeableness (standardized beta $=.54$ ), and openness (standardized beta $=.46$ ). Antonakis \& Dietz $(2011 \mathrm{a}$ ), who investigated the Ability Emotional Intelligence Measure found similar results (Multiple $\mathrm{R}=.69$ ), with significant predictors being intelligence, standardized beta $=.69$ (using the Swaps Test and a Wechsler scales subtest, the 40 -item General Knowledge Task) and empathy, standardized beta $=.26$ (using the Questionnaire Measure of Empathic Tendency)--see also Antonakis \& Dietz (2011b), who show how including or excluding important controls variables can fundamentally change results - thus, it is important to always include important controls like personality and intelligence when examining the predictive validity of ability and trait EI models.

Claims for the predictive power of EI are too extreme: Landy distinguishes between the "commercial wing" and "the academic wing" of the EI movement, basing this distinction on the alleged predictive power of EI as seen by the two currents. According to Landy, the former makes expansive claims on the applied value of EI, while the latter is trying to warn users against these claims. As an example, Goleman (1998) asserts that "the most effective leaders are alike in one crucial way: they all have a high degree of what has come to be known as emotional intelligence. ...emotional intelligence is the sine qua non of leadership". In contrast, Mayer (1999) cautions "the popular literature's implication-that highly emotionally intelligent people possess an unqualified advantage in life-appears overly enthusiastic at present and unsubstantiated by reasonable scientific standards." Landy further reinforces this argument by noting that the data upon which these claims are based are held in "proprietary databases", which means they are unavailable to independent researchers for reanalysis, replication, or verification. Thus, the credibility of the findings cannot be substantiated in a scientific way, unless those datasets are made public and available for independent analysis. 
In an academic exchange, Antonakis and Ashkanasy/Dasborough mostly agreed that researchers testing whether EI matters for leadership have not done so using robust research designs; therefore, currently there is no strong evidence showing that EI predicts leadership outcomes when accounting for personality and IQ. Antonakis argued that EI might not be needed for leadership effectiveness (he referred to this as the "curse of emotion" phenomenon, because leaders who are too sensitive to their and others' emotional states might have difficulty making decisions that would result in emotional labor for the leader or followers). A recently-published meta-analysis seems to support the Antonakis position: In fact, Harms and Credé found that overall (and using data free from problems of common source and common methods), EI measures correlated only $\mathrm{r}=.11$ with measures of transformational leadership. Interestingly, ability-measures of EI fared worst (i.e., $r=.04$ ); the WLEIS (Wong-Law measure) did a bit better $(r=.08)$, and the Bar-On measure better still $(r=.18)$. However, the validity of these estimates does not include the effects of IQ or the big five personality, which correlate both with EI measures and leadership. In a subsequent paper analyzing the impact of EI on both job performance and leadership, Harms and Credé found that the meta-analytic validity estimates for EI dropped to zero when Big Five traits and IQ were controlled for. Joseph and Newman meta-analytically showed the same result for Ability EI, but further demonstrated that self-reported and Trait EI measures retain a small amount of predictive validity for job performance after controlling Big Five traits and IQ. Newman, Joseph, and MacCann contend that the greater predictive validity of Trait EI measures is due to their inclusion of content related to achievement motivation, self efficacy, and self-rated performance.

NICHD Pushes For Consensus: The National Institute of Child Health and Human Development has recognized the divide on the topic of emotional intelligence explains the need for the mental health community to agree on some guidelines to describe good mental health and positive mental living conditions. In their section, "POSITIVE PSYCHOLOGY AND THE CONCEPT OF HEALTH," they explain, "Currently there are six competing models of positive health, which are based on concepts such as being above normal, character strengths and core virtues, developmental maturity, social-emotional intelligence, subjective well-being, and resilience. However, these concepts define health in philosophical rather than empirical terms. Dr. [Lawrence] Becker suggested the need for a consensus on the concept of positive psychological health...

EI, IQ and job performance: Research of EI and job performance shows mixed results: a positive relation has been found in some of the studies, in others there was no relation or an inconsistent one. This led researchers, Cote \& Miners (2006) to offer a compensatory model between EI and IQ, that posits that the association between EI and job performance becomes more positive as cognitive intelligence decreases, an idea first proposed in the context of academic performance (Petrides, Frederickson \& Furnham, 2004). The results of the former study supported the compensatory model: employees with low IQ get higher task performance and organizational citizenship behavior directed at the organization, the higher their EI. A meta-analytic review by Joseph and Newman also revealed that both Ability EI and Trait EI tend to predict job performance much better in jobs that require a high degree of emotional labor (where 'emotional labor' was defined as jobs that require the effective display of positive emotion). In contrast, EI shows little relationship to job performance in jobs that do not require emotional labor. In other words, emotional intelligence tends to predict job performance for emotional jobs only. A more recent study suggests that EI is not necessarily a universally positive trait. They found a negative correlation between EI and managerial work demands; while under low levels of managerial work demands, they found a negative relationship between EI and teamwork effectiveness. An explanation for this may suggest gender differences in EI, as women tend to score higher levels than men. This furthers the idea that job context plays a role in the relationships between EI, teamwork effectiveness, and job performance. Another interesting find was discussed in a study that assessed a possible link between EI and entrepreneurial behaviors and success. In accordance with much of the other findings regarding EI and job performance, they found that levels of EI only predicted a small amount of entrepreneurial behavior.

EI, self-esteem, and drug use: A 2012 study cross examined emotional intelligence, self-esteem, and marijuana dependence. Out of a sample of 200, 100 of which were dependent on cannabis and the other 100 emotionally healthy, the dependent group scored exceptionally low on EI when compared to the control group. They also found that the dependent group also scored low on self-esteem when compared to the control. Another study in 2010 examined whether or not low levels of EI had a relationship with the degree of drug and alcohol addiction. In the assessment of 103 residents in a drug rehabilitation center, they examined their EI along with other psychosocial factors in a 1 month interval 
of treatment. They found that participants' EI scores improved as their levels of addiction lessened as part of their treatment.

Expression of the problem: Rate of the success in the organizational environment being full of the competition and change depends on the ability of managers to play an effective leading role. Necessity of the change in the present situation (status quo) of the banking industry in Iran for its more effectiveness suggests this question mentally that that are required to flourish this industry. The managers of many organizations in the recent years have taken theory of the transformation- centered leadership styles, which is one of the theoretical frameworks in the world, into consideration. Many advantages have been identified for this style including it can refer to the job satisfaction, increase of the productivity of the organization and the reduction of the stress in the subordinates, as an example (Rush et al., 1997; Barling et al., 2000). Transformation- centered leadership is a part of the new paradigm of the leadership and suggests a process, which transforms and changes the individuals and correlates with the values, moral attributes and long-term objectives (Doherty et al., 1996).The pioneering and successful organizations have taken action to test the new managerial models of the transformation- centered leadership. It is for this reason that the transformation- centered leaders inculcate a vision into the followers which inspires the followers and motivates them to reach the extraordinary or beyond-of-expectation objectives and, more important, they admit and perceive it as their own view point and ideal (Avoilio et al., 1995).

In 1990, Burns and Bass expressed that the higher managers of the organizations can guide or direct their followers toward an excellent and beyond-of-expectation performance using the behavioral attributes of the transformation- centered leadership (Bass et al., 1990). In the subject of the leadership, the emotional intelligence is regarded as a determinant factor in the effective leadership. The emotional intelligence of a leader is the factor of creating the culture or a special working environment. Recently, the emotional intelligence has attracted itself the attention of most scientists and the results of the researchers suggest that the emotional intelligence in the success of the individuals and effectiveness of the organization is, at least, involved as much as the intelligence quotient (IQ) of the individuals (Goleman et al., 2002). Emotional quotient (EQ) includes the identification and control of the one self's emotions and excitements. In other words, a person who has a high emotional quotient combines three components of the emotions together successfully (the cognitive component, physiological component and behavioral component). Goleman believes that the high emotional intelligence explicates why the individuals with the average intelligence quotient (IQ) are more successful than those who have very higher intelligence quotient (IQ).Term of "emotional intelligence" was raised for the first timer by two psychologists named Mayer and Peter Solovey in 1990's. They asserted that those who are of the emotional intelligence can control their own affections and those of others, discriminate between the positive and negative consequences and use the affective information to guide the thinking process and personal measures (Goleman, 1995). For this reason, identification of the components of the transformation- centered leadership in selection of the new leaders and evaluation of the current leader is effective in the direction of this subject that how the emotional intelligence in the managers leads to the transformation-centered leadership in them; while providing this possibility that appropriate and effective teachings and strategies have been designed and implemented in order to reinforce the emotional intelligence and exercise the transformation- centered leadership.

Considering that the country is not of a researching precedence regarding the study of the leadership style of managers in the management of banks and, also, awareness of the level of emotional intelligence of the banks managers and relationship of these two cases to get her, this research deals with the survey of the relationship between the emotional intelligence and with the styles of the transformation- centered leadership. In other words, this research seeks for responding to this question that whether there exists a relationship between the emotional intelligence and transformation-centered leadership style in the studied sample or not. Somebody who has the emotional intelligence can control others and we stated in the transformation- centered discussion that the manager tries to create the change and transformation. Without controlling and exercising the control, manager cannot generate the transformation. As a result, it appears that both of them relate together positively which this affair has been led to the creation of the thought for the research.

Importance of the subject: In order to be able to remain in the today turbulent and competitive environment, the banks, also, such as the economical institutes must equip themselves with the new thoughts of the business. Determination of the business strategies and policies is to be pawned in the decisions of the economical unique managers. Leadership of the organizations of this type is of higher sensitivity when the leaders confront with the corresponding change; leadership of an organization looks 
for particular features for the conformity with the changes and for the purpose of the growth and survival in the new business environment. In this field, one of the personality components, which can assist the leaders and managers, is the emotional intelligence because the emotional intelligence is the ability of using the feeling of oneself and others in the individual and grouping behavior in order to acquire the maximum results with maximum satisfaction. Therefore, combination of the managerial knowledge and emotional intelligence in the management can be effective and facilitative to lead the individuals to achieve the objectives. In case of emerging the relationship between the emotional intelligence and transformation- centered leadership, it can be benefitted from the assessment and instruction to promote the emotional intelligence in order to employ the competent and deserved managers considering the need of country to transformation- centered management in the various sections. Banking industry is one of the most principal economical institutions, the most powerful and reliable supporting organization and the financial procuring for other economical institutes and families.

Theoretical foundations: Leader means to influence on others in order to reach the objectives, and the follower is a person who obeys the commands of leader.

Charisma: is one of the personal attributes, from amongst the ways of individual or group's influence, and is regarded as the ways of acquiring the social power.

Inspiration: leader creates the hope in the subset, introduces the future landscape as obvious and attainable one and persuades the individuals to raise their own expectations.

Mental encouragement: leader encourages the space of thinking and forces the individuals to think and reason before taking any action.

Individual considerations: As a trainer and instructor, the leader behaves with his/her followers and subset, develops them, invests the power/authority and faces with and behaves towards them based on their competence.

Ideal behaviors: On his/her own, the leader shows the self-sacrifice and is responsible for his/her own measures; shares with the in the happiness's, pleasures and ambitions and esteems and shows a determinant role practically.

Emotional intelligence in the organizational environment: The most appropriate domain to compare the emotional intelligence and intellectual intelligence is in the job environment because the individual in his/her own job environment, in addition to the scientific potencies (which result from the intellectual intelligence), uses his/her own affective abilities. For this reason, in the domain of developing the human resource in the organizations, concept of the emotional intelligence has been employed so that, in addition to the specialized abilities, the affective skills are to be taken into consideration. Researches of Goleman et al.(2002) show that the high levels of the emotional intelligence create a space in which the informational participation, trust, healthful risk taking and learning are to be shaped. On the contrary, the low emotional intelligence creates an atmosphere space being full of the fear and anxiety. Since the nervous or panic-stricken employees can have a high productivity in short term, their organizations may acquire the good results and outputs, but these results and outputs will not last much. Organizations are the environments, which require the inter-personal interactions. Performance of the various occupational functions, including service giving to the customers, receipt of the instructions and reports from the supervisor, cooperation and harmony with the employees have been intermingled with these interactions when the social interaction occurs, the emotional/affective awareness and regulation of the emotion becomes the important factors which affect on the quality of this type of interactions.

The employees who are of the higher emotional intelligence than others have the less vulnerability; also, commitment level and the transformational attributes in such employees are higher. They ask for the acquisition of the results which become useful not only for them but also for others and organizations (Scott-ladd et al., 2004). A large set of the researches regarding the emotional intelligence suggest that the individuals who have the higher emotional intelligence are the generator employees and happier, Tischler et al. (2002) This kind of the employees act more effective on the team works and are more profitable for the organization by acquiring the better working results, Daus et al. (2005) and are less exposed to the affliction with pessimism toward the work place than the other employees (Ferres et al., 2004). The other findings of the researchers suggested that the emotional intelligence is required in the effective performance and prevention from the stress. In addition, emotional intelligence is a predictor of more job satisfaction and less job rotation (Daus et al., 2005).therefore, it seems that the individuals who have higher emotional intelligence are more effective in the job environment and enjoy greater in their own professional life. Due to the positive personality and the sincerity they use and show in the relationships, such individuals spread a field of the "Affective Attractions" around themselves (Abraham, 1995). 
Emotional intelligence in the management: In his own researches in connection with the leadership, Bar-on (2005) reached this conclusion that there exists an average correlation between the emotional intelligence and leadership. He showed in his researches that the successful leadership correlates with the emotional intelligence almost up to $67 \%$. Various researches show the importance of such a criterion for the skills of the leadership. Burbach et al. (2004) studied the effect of the index of ability-centered emotional intelligence on the continuum of the multifactorial leadership. The data from 146 leaders and 649 followers were collected. In this research, a noticeable relationship was observed between the emotional intelligence and the whole leadership styles from the perceptive view point of the leaders, and it was specified that the perception of the leader about himself/herself can moderate the relationship between the emotional intelligence and transformation-centered leadership and the results related to the leadership style from the perspective of followers. In this book under the topic of "work along with the emotional intelligence", Goleman claims that, although the General Intelligence Quotient (IQ) is fixed relatively, but the emotional intelligence can be created, taught and improved by the practice, planning and psychotherapy. Thus, the organizations can test the emotional intelligence and teach that (Leban et al., 2004; Bryson et al., 2005) dealt with studying the relationship between the leadership skills and abilities of the emotional intelligence among the managers. The statistical population of this research was the managers who participated in two plans of the leadership development executed in the center for the creative leadership. 103 volunteers completed the Mayor's, Salovey's and Karoser's Emotional Intelligence Test (MSCEIT).

\section{Figure No 1: The main components of the transformation- centered leadership}

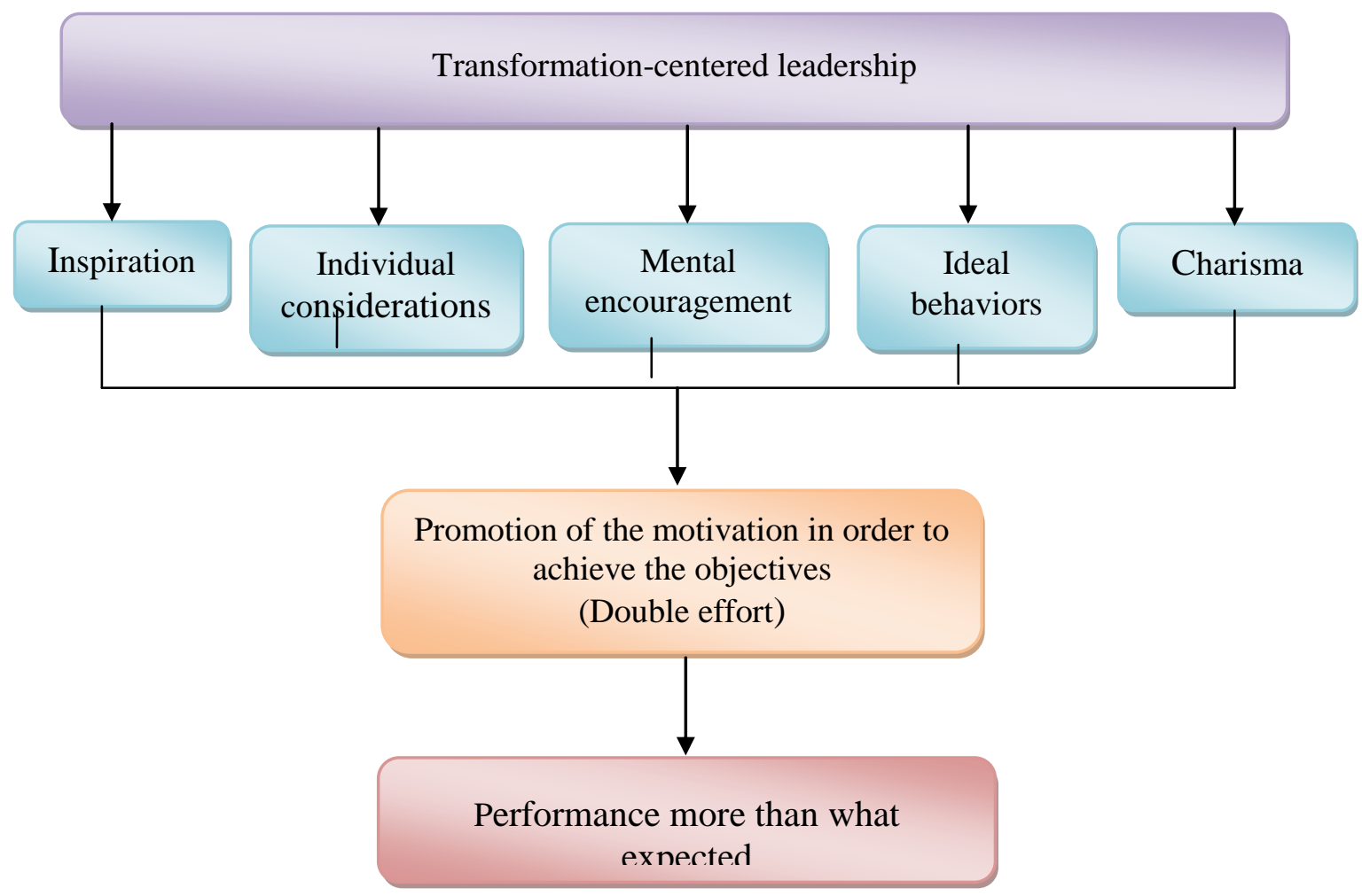

Goleman et al. (2002) considers the role of the emotional intelligence in the leadership of the organizations in quantity of $80 \%$ and regard the role of the logically reasoning intelligence only in quantity of $20 \%$. Results of the Goleman's researches showed that the manager who is of a much emotional intelligence and possesses the required experiences from the technical viewpoint will deal with the elimination of the group conflicts and weak points through more readiness than others will. Several witnesses confirm that the individuals who are of the emotional intelligence, namely those who recognize their own feelings well and guide them and, also, perceive the others' feelings and encounter with them effectively are successful in the all aspects of life, whether in the affective relationships or in the undocumented cases which lead to the achievement in the organizational policy (Bar-on, 2005). In addition, researches have shown that the managers with high emotional intelligence achieve $80 \%$ to $85 \%$ of their objectives and are of the more success in the job and individual relationships, Goleman et al. (2002). In the studies conducted by Goleman, he has surveyed 500 organizations. The individuals 
acquired the maximum score from viewpoint of the criteria of emotional intelligence have placed in the higher levels of the organization (Barling et al., 2000). Emotional intelligence is one of the factors for the strategically development of the human resources. From the Goleman's viewpoint, the concept of the emotional intelligence must be taken into consideration in the strategies in the strategies of the leadership development. Today, many organizations are exposed to the change and any change requires the employees and managers who are conformable and adapted/ well adjusted. Researches show that the best way in the successful management of the present difficulties is to maximize the ability of the effective usage of the leadership attributes. These attributes include emotional self-consciousness and correct selfevaluation, innovation, empathy, relationships/ communications, right decision-making, effectiveness, conformability, adaptability and self-management. All technical skills and mentioned capabilities, more than being management skills, are the capabilities of managing the emotional intelligence. Quality of these eight capabilities of the emotional intelligence seems very important (Sivanathanniroshaan et al., 2002).

Emotional intelligence of the leaders and effectiveness of the performance: Capabilities of the emotional intelligence in the leaders affect very much on their effective performance. Managers and directors with the self-consciousness and self-evaluation capabilities in the interaction of the job and individual relationships encounter less with problem while facing with others and admit their own mistakes and realize their own weak and strength points with a realistic self-consciousness. The managers with capability of this task, while encountering with problems, show useful and active reaction, not defensive reaction. As a result, they use the opportunities in the best way. The directors with the capability of empathy use the participation of employees in the working process and trust in them. The managers with ability of establishing the relational skills manage the chaos well in the critical conditions put importance on the group work and participation of the employees and welcome the bilateral negotiations regarding the significant subjects. Directors and managers having the capability of high emotional intelligence take action strongly and are responsible and take the responsibility. Influential managers intend to encourage the others for the expression of the idea and belief and participation in the decision makings and working processes, and instead of driving their employees away from themselves, benefit from their support and protection and, finally, the managers who are of the self management, which is out of the most important capabilities of the emotional intelligence, will not get involved in anger or stress while confronting with the rapid environmental changes and transformations or appearing the conflict in the job environment and will prevent from the expected consequences through the rapid and fast respondence to the problems (Burbach et al., 2004). On the basis of George's opinion, the leader who are intelligence emotionally can promote the effectiveness in all levels of the organization (Doherty et al., 1996).The emotional intelligence of a leader plays an import role in the quality and effectiveness of his/her social interactions with the other individuals.

\section{Literature and back ground of the research}

In his analysis, Hebert et al. (2011) used the analysis of correlation between two variables. His research sample was conducted for 30 primary, middle and high schools' classrooms and 5 teachers who were the school teachers too which the results showed that the teachers who were principal and acquired the less score did not use the model of the transformation-centered management and, also, their score in the model of the non-transformation-centered management became less. The other results of this research showed that the weak and strength points in the domain of the emotional intelligence must be identified in order to develop the leadership skills effectively. In addition, this identification must be accompanied by the reinforcement of the transformation-centered management. Harms et al. (2010) studied the subject of this research and came to this conclusion that the emotional intelligence has the significant relationship with transformation-centered management and the other behaviors of the management, which acquired theirs results from 62 independent samples. In a research under the topic of relationship of the emotional intelligence of managers and organizational climate with organizational culture of learning in the Iranian Oil National Company, Moshabaki et al. (2010) reached these conclusions that findings of the research suggest that the high emotional intelligence of managers has a positive and high correlation with the organizational climate and organizational culture of learning. Considering the above materials, organizations must go ahead toward the learner organizations so that they can respond to the daily requirement of the clients, and the emotional intelligence of employees plays a determinate role in this connection. The research searches for finding a relationship between these two basic variables among the offices of Ministry of Education of regions No1 and 2 and of Khoramabad. 
In this research, Cox et al. (2008) refers to the detection of the relationship between the intellectual models and emotional skills. The emotional intelligence, with the positive and coherent theories, is of the human behavior and suggests based on the research's findings that these concepts are to be applied in the planning of consulting and educational works of the employees in order to facilitate the positive growth. In a research, Mokhtaripur et al. (2008) dealt with studying the relationship between the emotional intelligence and the leadership outputs (Bernard Bass's model) of the educational groups' managers in the Isfahan University whose results of the research showed that there exists a significant relationship between the emotional intelligence and leadership outputs of the educational groups' managers. Pursuing to find a relationship between the emotional intelligence and adaptability with the complicate conditions of the job environment, Gerits (2005) showed that the female nurses who were of a high emotional intelligence complained less about the difficulty of work, absented and left the service less. The male nurses who complained less about the difficulty of work were those who benefitted from the problem solving skills and stress-tolerating skills. A number of researches refer to the importance of feelings in the perception of negative reactions against the organizational change and success or failure in the efforts to change (Kiefer, 2005).

Jordan (2004) has identified the capability of emotional intelligence in the prediction of a limit of the personal competences/merits in the job environment, which help the successful organizational change. This subject can provide the employees, within the change period, with a range of the useful skills as well as the skills, including the intermediacy, leadership cycle and usage of the social networks. Results of the research carried out by Prati et al. (2003) suggest this fact that the individuals who have the higher emotional intelligence act more successfully in the situations, which require flexibility and social effectiveness. Mandell et al. (2003) tested a predicting relationship for the model of the transformationcentered management and emotional intelligence. In this research, gender of the management in the intensity of this relationship is to be tested as well, and it has shown that such a relationship between emotional intelligence and transformation-centered leadership is significant in the confidence level of $95 \%$, but there is no relationship between the gender and these two agents.

Hypotheses of research: Main hypothesis: There exists a significant relationship between the rate of emotional intelligence and transformation centered leadership in the banks' managers.

\section{Sub hypotheses are as follows}

- There exists a significant correlation between the banks' managers and their components of charisma.

- There exists a significant correlation between the emotional intelligence of the banks' managers and their component of the ideal behaviors.

- There is a significant correlation between the emotional intelligence of the banks' managers and their component of the mental encouragement.

- There is a significant relationship between the emotional intelligence of the banks' managers and their component of the inspiration.

- There exists a significant correlation between the emotional intelligence of the banks' managers and their component of the individual considerations.

Scope of research: Emotional intelligence is from amongst the psychological concepts, which enter into the job domain in the organizations, and leadership is one of the managerial subjects. Therefore, the subject's realm of research is psychological-managerial one, the place domain of research is governmental banks of the fifth zone of Tehran municipality and the time scope of the research is the second half of the year of 2012.

\section{Type of study, method and how to execute the research}

From view point of objective, this research is of the descriptive and applied type which searches for the description and explication of the manner of the relationship between the emotional intelligence and behaviors of the transformation-centered leadership in the managers of research is governmental banks of the governmental banks of the fifth zone of Tehran municipality which has been conducted in the surveying form.

Tools of data collection: In order to execute this research, the texts and literature of research were studied by the library reading after the selection of the research's subject. Then, with regard to the 
research's subject, (MLQ) questionnaire was used to measure the behaviors of the transformationcentered leadership and (EQ-I) questionnaire was applied to measure the index of the emotional intelligence and the required data were hereby collected.

Validity and reliability of the MLQ questionnaire: In 2012, the writers executed a test on the equal subjects twice in order to study the reliability of this questionnaire. The obtained results are of the correlation, suggesting the appropriate reliability of this questionnaire. In order to determine the reliability of the questionnaire, the Cronbach Alpha Coefficient has been used which this Coefficient was obtained 0.92 validity of this questionnaire was carried out using Deldhi methods, preliminary distribution of questionnaire and the receipt of the reforming view points in 2012.

Statistical universe, sample volume, sampling method and mode of the data analysis: The statistical universe of this research is the managers of the governmental banks and their employees in the level of the fifth zone of the Tehran municipality. In this research, the sampling method is the judging-clusteringtargeting method. The Cronbach Alpha has used to specify the reliability of the research. Quantity of alpha higher than 0.90 suggests the high validity of the research's tools $(a \geq 0.09)$. Thus, the quantity of the Cronbach Alpha calculated for the questionnaire of this research is 0.92 approximately, which suggests the high validity of the research's tool. In table No 1, quantity of the Cronbach Alpha calculated for each one of the component parts of the research has been presented and quoted.

Table 1: Quantity of Cronbach Alpha calculated for each component parts of the research

\begin{tabular}{lll}
\hline Main components & Number of questions & Quantity of Cronbach Alpha \\
\hline Emotional intelligence & 4 & $85 \%$ \\
Charisma & 4 & $95 \%$ \\
Ideal behaviors & 4 & $92 \%$ \\
Mental encouragement & 4 & $95 \%$ \\
Inspiration & 4 & $94 \%$ \\
Individual considerations & 4 & $91 \%$ \\
Total & 24 & $92 \%$ \\
\hline
\end{tabular}

\section{Results and Data Analysis}

Study and analysis of the first to fifth hypotheses $\left(\mathbf{H}_{\mathbf{1}}\right.$ to $\left.\mathbf{H}_{5}\right)$ : In order to study these hypotheses, the Test of the Pearson Correlation Coefficient (P) is used. In order to specify that whether the data of this research are normal or not, the Kolmogorov-Smirnov Test (K-S) was used. Considering that the results obtained from the K-S test show that the rate of 'Sig' acquired for all variables is higher than 0.05 , data of the present research are of the normal distribution. Thus, the Test of the Pearson's Correlation Coefficient can be used to assess the truth or falsity of the research's hypotheses. Table No 1 shows the results of the above test for the first to fifth hypotheses. As it is understandable from the above table, a powerful positive and significant relationship is observed between the emotional intelligence of the employees and five components of charisma, ideal behaviors, mental encouragement, inspiration and the individual considerations.

Analysis of the effectiveness of quintuple components using the T-test: After the survey and confirmation of the existence of a relationship among the quintuple components of emotional intelligence with charisma, ideal behaviors, mental encouragement, inspiration and individual considerations of employees, the study of their effectiveness is dealt with using the T-test in this section. For this purpose, one sample T-test is used.

Table 2: Results of one sample T-Test in order to study the effectiveness of quintuple components of the research

\begin{tabular}{lllll}
\hline Components & T & Df & Sig. (2-tailed) & Std.Deviation \\
\hline Charisma & 10.256 & 125 & .000 & 1.23456 \\
Ideal behaviors & 7.981 & 125 & .000 & 1.98347 \\
Mental encouragement & 9.226 & 125 & .000 & 1.78631 \\
Inspiration & 8.173 & 125 & .000 & 1.76345 \\
Individual considerations & 12.458 & 125 & .000 & 1.58123 \\
\hline
\end{tabular}

Results obtained from the T-test indicated that the quintuple components of the research, including: charisma, ideal behaviors, mental encouragement, inspiration and the individual considerations are 
effective on the emotional intelligence of employees in the domain of research, namely the governmental banks' managers of the fifth zone of Tehran municipality. In other words, in addition to the existence of the positive and significant relationship between these components and emotional intelligence and they must be taken into consideration highly in order to reach the success in the execution of the transformation-centered leadership.

Ranking of the quintuple components by use of Friedman's Test: In this section, in order to determine the most important components affecting on the employees, out of the quintuple components of research and, also, determination of the ranks related to each one of them, Friedman's variance analysis test is used. The result of analyzing the data of the questionnaire by use of the Friedman's variance analysis test has been presented and quoted in table No 3 .

Table 3: Results of Friedman's Test in order to compare the components of research

\begin{tabular}{llllll}
\hline & Number & $\begin{array}{l}\text { The calculated Chi } \\
\text { square quantity }\end{array}$ & Df & ${ }^{*}$ Sig & $\begin{array}{l}\text { Result of } \\
\text { test }\end{array}$ \\
\hline $\begin{array}{l}\text { Study of effect of equality of the rank of } \\
\text { each one of the quintuple components } \\
\text { on the managers' emotional } \\
\text { intelligence }\end{array}$ & 126 & 10.543 & 125 & $0.000 \begin{array}{l}\text { Lack of } \\
\text { the } \\
\text { equality } \\
\text { of ranks }\end{array}$ \\
\hline
\end{tabular}

${ }^{*} \alpha=0.05$, a: Friedman Test

Above table relates to the Friedman's Test analysis, which shows the number of the data of each tool, Chisquare static quantity $\left(c^{2}\right)$, freedom degree and Sig quantity respectively. As it is specified from above table, rate of Sig is less than 0.05 . For this reason, claim of equality of the ranks (priorities) of the quintuple components affecting on the emotional intelligence of employees in the researched case is denied. In other words, it can be said by confidence level of 0.95 that there exists a significant difference between the components and they have the different and diverse priorities. Therefore, the second output of Friedman's Variance Analysis test is used to determine the priority or sequence of each one of the quintuple components. These results have shown in table No 4.

Table 4: Results of giving priority to the quintuple components using the Friedman Test

\begin{tabular}{lll}
\hline Priority & Components & Average ranks \\
\hline 1 & Inspiration & 3.6720 \\
2 & Ideal behaviors & 3.0714 \\
3 & Mental encouragement & 3.0079 \\
4 & Individual considerations & 2.7222 \\
5 & Charisma & 2.7143 \\
\hline
\end{tabular}

Considering that the Likert 5 Choice Spectrum has been used to collect the data and that spectrum has been put in order from the low to high for questionnaire of this research, the higher the average of ranks, the more important is that variable. Thus, it can be concluded that the sequence of priority or importance of each one of the quintuple components being effective on the emotional intelligence of employees has been taken into consideration in the table No 4 .

\section{Conclusion and Suggestions}

In this research, questionnaire of transformation-centered leadership was completed by the banks' employees and questionnaire of the emotional intelligence was completed by the banks' managers. The results obtained from testing of the first to fifth sub hypotheses suggest that there exists significant relationship between the emotional intelligence with components of charisma, inspiration, ideal behaviors, mental encouragement and individual considerations, which are the components of transformation-centered leadership. Results of research represent the existence of a powerful relation between the emotional intelligence and transformation-centered leadership in the bank's managers. Leaders who can disclose the more transformation-centered behaviors will identify better their own emotional states/ moods and express it for others appropriately. They are able to manage and control the positive and negative emotions in themselves and others. Banks are suggested to promote the instruction 
of in-service behavior/ moral of the strategic management arisen from the ideal behaviors and justification of conformity and comparison of the appropriate and inappropriate behaviors in the job environment in order to raise the spirit of transferability and, also, allow the managers to use the recreational leave to raise the fresh spirit in the job environment. In order to increase the inclination toward the cooperation, managers' reward based on the performance, customers' and employees' satisfaction considering his/ her job environment (for example activity in the in appropriate and critical conditions) is taken into consideration.

Suggestions for Future Researches: It is suggested that the researchers interested in this domain to study the relationship between the emotional intelligence and customer-centered management in the future readings and studies and to compare the obtained result with the results of this research. Meanwhile, survey of the relationship of the citizenship management with emotional intelligence is to be studied and compared with the studied relationships in the previous suggested part. Meanwhile, these two relationships in connection with transformation-centered management are suggested.

\section{Limitations of the Research}

- Expansion of the banking systems in Iran. For this reason, the governmental banks of the fifth zone of Tehran municipality have been selected out of this expanded sample.

- Lack of cooperation of 32 bank's managers in the case of respondence to questionnaire.

- Abstractiveness of the cases raised in this research, which was led to spend much time on their description and explanation for the respondents.

\section{References}

Abraham, R. (1995).Emotional Intelligence in Organizations: A noitazilautpecnoC. Genetic, Social, and General Psychology Monographs, 125(2), 209-224.

Antonakis, J. \& Dietz, J. (2011a). Looking for Validity or Testing It? The Perils of Stepwise Regression, Extreme-Scores Analysis, Heteroscedasticity, and Measurement Error. Personality and Individual Differences, 50(3), 409-415.

Antonakis, J. \& Dietz, J. (2011b). More on Testing for Validity Instead of Looking for It. Personality and Individual Differences, 50(3), 418-421.

Avoilio, B. J. \& Bass, B. M. (1995). Individual consideration viewed multiple levels of analysis: A multi-level framework for examining the diffusion of transformational. leadership Leadersh Q., 6(2), 199-218.

Barling, J., Slater, F. \& Kelloway, E. K. (2000). Transformational leadership and emotional Intelligence: An exploratory Study. Leadersh Organ Dev J., 21(3), 123-7.

Bar-on, R. (2005). The bar-on model of emotional-social intelligence. American Management Association, 27-31.

Bass, B. M. \& Avolio, B. J. (1990). The implications of transactional and transformational leadership for individual, team and organizational development. Res Organ Change Dev., 4, 231-72.

Bryson, D. \& Karen, L. (2005). Managerial success and derailment: the relationship between emotional intelligence and leadership. doctoral thesis fielding graduate institute, 133-135.

Burbach, J. \& mark, E. (2004). Testing the relationship between emotional intelligence and full range leadership as moderated by cognitive style and self-concept. PhD dissertation the university of Nebraska linkoln Sep 2004 available at, www.UMI.COM.

Cot, ${ }^{\wedge}$ E. S. \& Miners, C. T. H. (2006). Emotional intelligence, cognitive intelligence and job performance. Adm. Sci. Q., 51, 1-28.

Cox, J. E. \& Nelson, D. B. (2008). Quantifying Emotional Intelligence: The Relationship between Thinking Patterns and Emotional Skills American Counseling Association. 5999 Stevenson Avenue, Alexandria, VA 22304. Web site: http://www.counseling.org.

Daus, C. S. \& Ashkanasy, N. M. (2005). The Case for the Ability-Based Model of Emotional Intelligence in Organizational Behavior. Journal of Organizational Behavior, 26(4), 453-466.

Doherty, A. Y. \& Danylchuk, K. E. (1996). Transformational and transactional leadership in interuniversity athletics management. J Sport Manage., 10, 254-68.

Ferres, N. \& Connell, J. (2004). Emotional Intelligence in Leaders: An Antidote for Cynicism Towards Change? Strategic Change, 13(2), 61-71.

Fiori, M. \& Antonakis, J. (2011). A process-oriented approach to emotional intelligence. The International Society for the Study of Individual Differences. London, UK. 
Gerits, L. (2005). Emotional Intelligence Profiles of Nurses Caring for People with Severe Behavior Problems. Personality and Individual Differences, 36, 1, 33-43.

Goleman, D., Boyatzis, R. \& McKee, A. (2002). Primal Leadership: Realizing the Power of Emotional Intelligence. Boston: Harvard Business School Press Human Relations, 48(2), 97-125.

Goleman, D. (1995). Emotional intelligence: why it can matter more than IQ? New York: bantam book.

Grubb, W. L. \& McDaniel, M. A. (2007). The fakability of Bar-On's emotional quotient inventory short form: Catch me if you can. Hum. Perform, 20, 43-59.

Harms, P. D. \& Crede, M. (2010). Emotional intelligence and transformational and transactional leadership : A Meta - Analysis. Journal of leadership \& Organizational Studies, 17(1), 5-17.

Hebert, G. \& Elizabeth, B. (2011). The Relationship between Emotional Intelligence, Transformational Leadership, and Effectiveness in School Principals .Educational Policy Studies Dissertations, 66.

Jordan, P. J. (2004). Dealing with Organizational Change: Can Emotional Intelligence Enhance Organizational Learning? International Journal of Organizational Behavior, 8(1), 456-47.

Kiefer, T. (2005). Feeling Bad: Antecedents and Consequences of Negative Emotions in Ongoing Change. Journal of Organizational Behavior, 26(8), 875-897.

Landy, F. J. (2005). Some historical and scientific issues related to research on emotional intelligence. Journal of organizational Behavior, 26, 411-424.

Leban, W. \& Zulaufcarol, U. (2004). linking emotional intelligence abilities and transformational leadership styles. The leadership \& organization development journal, 25(7), 554-564.

Leuner, B. (1966). Emotional intelligence and emancipation. Praxis Kinderpsychol. Kinderpsychiatrie, 15, 193-203

Locke, E. A. (2005). Why emotional intelligence is an invalid concept. Journal of organizational Behavior, $26,425-431$.

Mandell, B. \& Pherwani, S. (2003). Relationship between emotional intelligence and transformational leadership style : a gender comparison. Journal of Business and psychology, 17(3), 387 - 404.

Matthews, G., Zeidner, M. \& Roberts, R. D. (2001). Does emotional intelligence meet traditional standards for an intelligence? Emotion, 1, 196-231.

Mayer, R. E. (1999). The promise of educational psychology: Vol. 1,Learning in the content areas. Upper Saddle River, NJ: Prentice Hall.

Mayer, J., Roberts, R. \& Barsade, R. (2008). Human Abilities: Emotional Intelligence. The Annual Review of Psychology is online at http://psych.annualreviews.org

Mokhtaripur, M., Siadat, S. A. \& Sholeh, A. (2008). A study of the relationship between the emotional intelligence and leadership out puts (Bernad boss's model) of the educational groups' managers in the Isfahan University. college of psychology and the education/ educational sciences, the Isfahan university.

Moshabaki, A. \& Vahab, K. S. (2010). Relationship of the affective/ emotional intelligence of managers and organizational climate with the organizational culture of learning in the Iranian national oil company. Magazine of the applied sociology, twentieth year, 3, 51 - 74.

Petrides, K. V., Frederickson, N. \& Furnham, A. (2004). The role of trait emotional intelligence in academic performance and deviant behavior at school. Personality and Individual Differences, 36, 277-293.

Prati, L. M., Douglas, C., Ferris, G. R., Ammeter, A. P. \& Buckley, M. R. (2003). Emotional Intelligence, Leadership Effectiveness, and Team Outcomes. The International Journal of Organizational Analysis, 11(1), 21-40.

Roberts, R. D., Zeidner, M. \& Matthews, G. (2001). Does emotional intelligence meet traditional standards for an intelligence? Some new data and conclusions. Emotion, 1, 196-231.

Rush, M. C., Thomas, J. C. \& Lord, R. J. (1997). Implicit leadership theory: A potential threat to the internal validity of leader. Behavior Questionnaires, 20(1), 93-110.

Salovey, P. \& Mayer, J. D. (1990). Emotional intelligence. Imagination, cognition and personality, 9, 185211.

Schulte, M. J., Ree, M. J. \& Carretta, T. R. (2004). Emotional intelligence: Not much more than g and personality. Personality and Individual Differences, 37, 1059-1068.

Scott-Ladd, B. \& Chan, C. C. A. (2004). Emotional Intelligence and Participation in Decision-Making: Strategies for Promoting Organizational Learning and Change. Strategic Change, 13(2), 95-105.

Sivanathanniroshaan, K. \& Fekken, G. \& Cynthia, O. (2002). Emotional intelligence moral reasoning and transformational leadership. Leadership \& Organization Development Journal, 23(4), 198-204.

Tischler, L., Biberman, J. \& McKeage, R. (2002). Linking Emotional Intelligence, Spirituality and Workplace Performance: Definitions, Models and Ideas for Research. Journal of Managerial Psychology, $17(3), 203-218$. 